Review

\title{
Food Addiction in the Light of DSM-5
}

\section{Adrian Meule ${ }^{1,2, *}$ and Ashley N. Gearhardt ${ }^{3}$}

1 Institute of Psychology, University of Würzburg, Marcusstr. 9-11, Würzburg 97070, Germany

2 Hospital for Child and Adolescent Psychiatry, LWL University Hospital of the Ruhr University Bochum, Heithofer Allee 64, Hamm 59071, Germany

3 Department of Psychology, University of Michigan, 530 Church Street, Ann Arbor, MI 48109-1043, USA; E-Mail: agearhar@umich.edu

* Author to whom correspondence should be addressed; E-Mail: adrian.meule@uni-wuerzburg.de; Tel.: +49-931-31-8-08-34; Fax: +49-931-31-8-24-24.

Received: 24 July 2014; in revised form: 21 August 2014 / Accepted: 25 August 2014 /

Published: 16 September 2014

\begin{abstract}
The idea that specific kind of foods may have an addiction potential and that some forms of overeating may represent an addicted behavior has been discussed for decades. In recent years, the interest in food addiction is growing and research on this topic lead to more precise definitions and assessment methods. For example, the Yale Food Addiction Scale has been developed for the measurement of addiction-like eating behavior based on the diagnostic criteria for substance dependence of the fourth revision of the Diagnostic and Statistical Manual of Mental Disorders (DSM-IV). In 2013, diagnostic criteria for substance abuse and-dependence were merged, thereby increasing the number of symptoms for substance use disorders (SUDs) in the DSM-5. Moreover, gambling disorder is now included along SUDs as a behavioral addiction. Although a plethora of review articles exist that discuss the applicability of the DSM-IV substance dependence criteria to eating behavior, the transferability of the newly added criteria to eating is unknown. Thus, the current article discusses if and how these new criteria may be translated to overeating. Furthermore, it is examined if the new SUD criteria will impact future research on food addiction, for example, if "diagnosing" food addiction should also be adapted by considering all of the new symptoms. Given the critical response to the revisions in DSM-5, we also discuss if the recent approach of Research Domain Criteria can be helpful in evaluating the concept of food addiction.
\end{abstract}


Keywords: DSM-IV; DSM-5; substance dependence; substance use disorder; gambling; food addiction; obesity; binge eating; craving; RDoC

\section{Introduction}

The idea that specific kind of foods may have an addiction potential and that overeating such as in binge-related eating disorders or obesity may represent a form of addicted behavior has been discussed for decades. The term food addiction was first introduced in the scientific literature in 1956 by Theron Randolph [1]. Although comparisons between addiction and eating behavior were sporadically drawn in the following decades [2-8], approaches to systematically examine and define food addiction were not pursued until the early 2000s. Particularly, a substantial increase in the number of publications using the term food addiction can be observed since 2009 [9].

This increased scientific interest in this topic was in part driven by the rise of neuroimaging and subsequent findings that obesity and binge eating are associated with alterations in dopaminergic signaling and food-cue elicited hyperactivation of reward-related brain areas which are comparable to processes seen in drug users [10,11]. Those findings were further complemented by animal models showing addiction-like behaviors and neuronal changes in rodents after some weeks of intermittent access to sugar [12]. In the current article, we will not go into further detail about those lines of research and refer the reader to recent works on those topics [13-17]. Instead, we will focus on the phenomenological similarities between substance dependence and some forms of overeating in humans.

\section{Parallels between Diagnostic and Statistical Manual of Mental Disorders (DSM-IV) Substance Dependence Criteria and Overeating}

The diagnostic criteria for substance dependence in the fourth revision of the Diagnostic and Statistical Manual of Mental Disorders (DSM-IV) included (1) tolerance, defined as consuming increasing amounts of a substance to achieve the same effects or experiencing diminished effects with continued use of the same amounts; (2) withdrawal symptoms when the substance is not consumed or using the substance to avoid withdrawal symptoms; (3) using the substance in larger amounts or over a longer period than intended; (4) a persistent desire or unsuccessful efforts to cut down substance use; (5) increased time effort to obtain or use the substance or recover from its effects; (6) reduction of social, occupational, or recreational activities because of substance use; and (7) use of the substance despite a persistent physical or psychological problem caused or exacerbated by the substance [18]. Substance dependence could be diagnosed when a clinically significant impairment or distress was present and at least three symptoms were met in the past year.

There are numerous articles in which the applicability of those DSM-IV substance dependence criteria and other features of addicted behavior to bulimia nervosa (BN), binge eating disorder (BED), obesity, or overeating in general are discussed [19-30]. However, the translation of substance dependence criteria to eating behavior is not straightforward and, as a result, there is some disagreement among researchers about the precise definitions of food addiction symptoms [31-35]. 
Although empirical evidence for the applicability of some DSM-IV addiction criteria to eating, such as tolerance and withdrawal, is mostly based on animal studies [12], all of the seven symptoms conceivably can be found in humans [26]. Compelling support for this was provided by a study by Cassin and von Ranson [36], in which almost all participants with BED received a diagnosis of substance dependence when the term substance was replaced with binge eating in a diagnostic interview. The authors noted, however, that participants' responses may have been influenced by demand characteristics and that reliability and validity of their interview assessment was uncertain [36].

\section{Yale Food Addiction Scale (YFAS)}

In an attempt to overcome mixed definitions of food addiction symptoms and to provide a standardized measure for the assessment of food addiction, the YFAS was developed [37,38]. This 25-item instrument measures the presence of food addiction symptoms based on the DSM-IV substance dependence criteria (i.e., seven symptoms). Additionally, two items assess a clinically significant impairment or distress as a result of overeating. When both a clinically significant impairment or distress is present and at least three out of the seven symptoms are met, then food addiction can be "diagnosed". Prevalence rates of these food addiction diagnoses according to the YFAS range between approximately $5 \%-10 \%$ in non-clinical samples [37,39-42], $15 \%-25 \%$ in obese samples [43-47], and 30\%-50\% in morbidly obese bariatric patients or obese individuals with binge eating disorder [48-51].

The most common food addiction symptom as assessed with the YFAS is a persistent desire or unsuccessful efforts to cut down or control eating [42,52]. Among obese individuals, almost all participants fulfill this criterion [46,48-50,53]. Other commonly endorsed symptoms are continued eating despite physical or psychological problems and tolerance, particularly in obese samples (ibid.). The remaining symptoms (consumption of large amounts or over a longer period than intended, spending much time obtaining food or eating or recover from its effects, giving up important activities, and withdrawal symptoms) are less common, particularly in non-clinical samples [42,52], but are nonetheless endorsed by a substantial proportion of obese individuals [48-50,53].

\section{Substance Dependence Criteria in DSM-5}

In the newly revised version of the DSM, the diagnostic criteria for substance abuse and-dependence were merged such that criteria for substance use disorders (SUDs) now additionally include (1) failure to fulfill major role obligations at work, school, or home as a result of substance use; (2) continued substance use despite social or interpersonal problems caused or exacerbated by substance use; and (3) recurrent substance use in situations in which it is physically hazardous [54]. Moreover, the DSM-IV substance abuse criterion of having legal problems was dropped, but a newly created symptom of craving, or a strong desire or urge to use the substance was incorporated (Table 1). Three levels of severity can now be specified ranging from mild (presence of two to three symptoms) to moderate (presence of four to five symptoms) to severe (presence of six or more symptoms).

Notably, SUD symptoms also differ across substances (Table 1). For example, although there is an intoxication and withdrawal syndrome described for caffeine, the other symptoms do not apply for 
caffeine and, thus, there is no caffeine use disorder. Vice versa, although all of the eleven symptoms apply to tobacco, there is no intoxication described. Finally, there is no withdrawal syndrome described for hallucinogens, for example phencyclidine, and inhalants.

\section{Parallels between New DSM-5 Criteria and Overeating}

\subsection{Craving}

Craving refers to an intense desire to consume a substance and frequent experiences of craving are a core feature of SUDs [55]. However, the term craving does not only refer to drug-related, but also to other substances like food or non-alcoholic beverages [56]. In Western societies, individuals usually crave foods that are high in sugar or fat (or both) and, thus, highly palatable. Accordingly, the most often craved food is chocolate, followed by pizza, salty foods, ice cream and other sweets and desserts [57] (but note there also cultural differences in the types of food craved [58]). These same types of foods are more likely to be consumed in an addictive-like manner as assessed by the YFAS [39]. As such, experiences of craving are a prime example of the similarities between eating and substance use. Similarly, activation patterns of neuronal structures underlying craving experiences largely overlap across different substances, including food [15,59-61]. Overeating is associated with more intense and more frequent experiences of food craving. For example, higher scores on self-reported food craving measures have been found in patients with BN, BED, or obesity [62,63]. Similarly, food addiction as measured with the YFAS is also related to higher self-reported food craving $[44,45,64]$. Thus, the criterion of frequently experiencing craving or a strong urge to consume a substance can be translated to food and represents an important symptom in food addiction.

\subsection{Failure to Fulfill Major Role Obligations}

We are not aware of any study that specifically investigated a failure to fulfill major role obligations at work, school or home resulting from addiction-like eating. Although this may likely occur in the case of morbid obesity as a result of reduced mobility, it is questionable if this also can be a direct consequence of eating behavior. Based on the wording of the DSM-5, future studies may ask participants if they neglect things like work, school, friends, family, or household chores because of the way they eat or if they are not doing well at school or work because of the way they eat. However, we suspect that, like tobacco, this symptom may not be a core aspect of addiction-like eating due to a lack of intoxication syndrome. 
Table 1. Substance use disorder criteria according to the Diagnostic and Statistical Manual of Mental Disorders (DSM-5) and possible corresponding food addiction criteria.

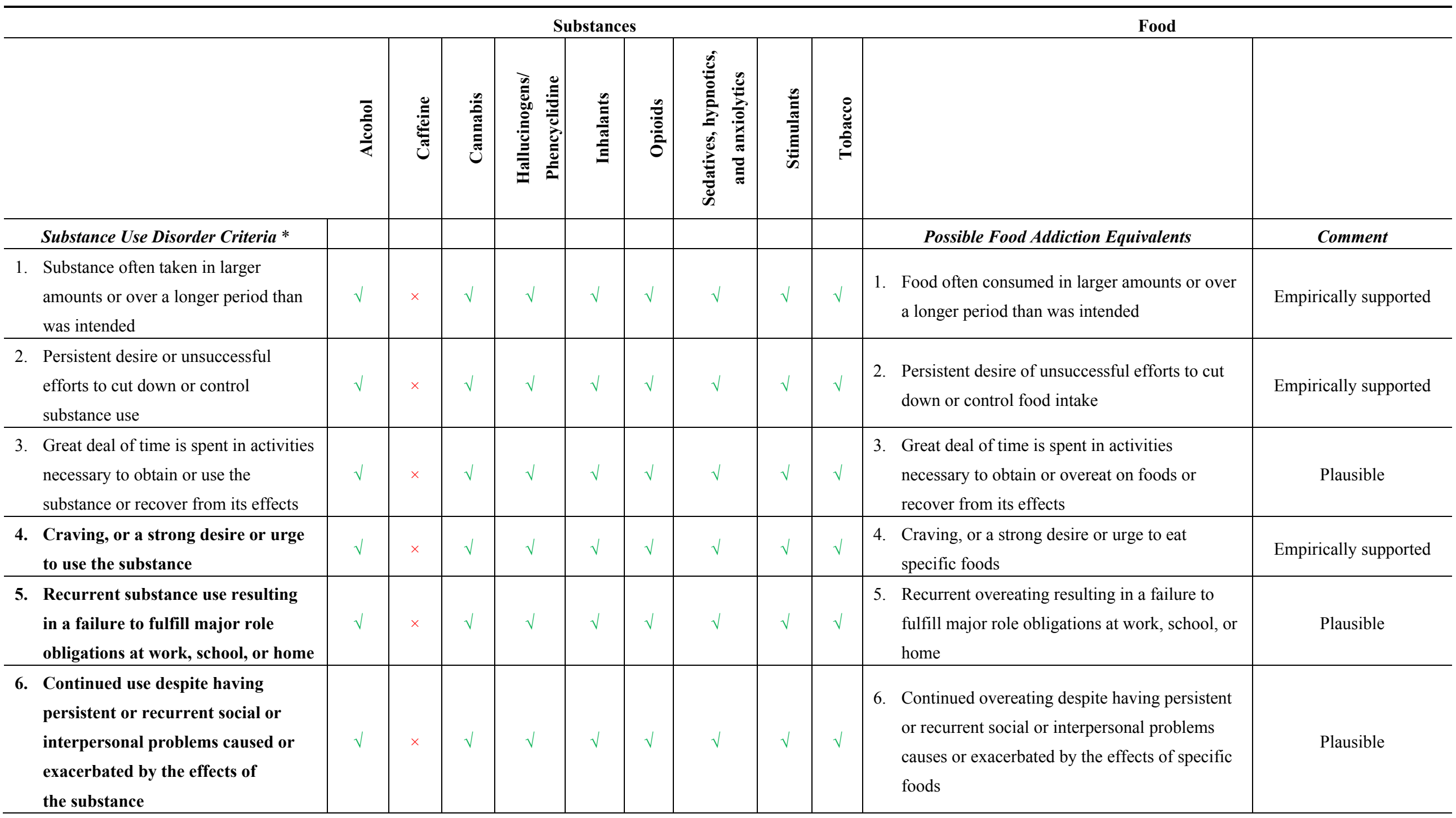


Table 1. Cont

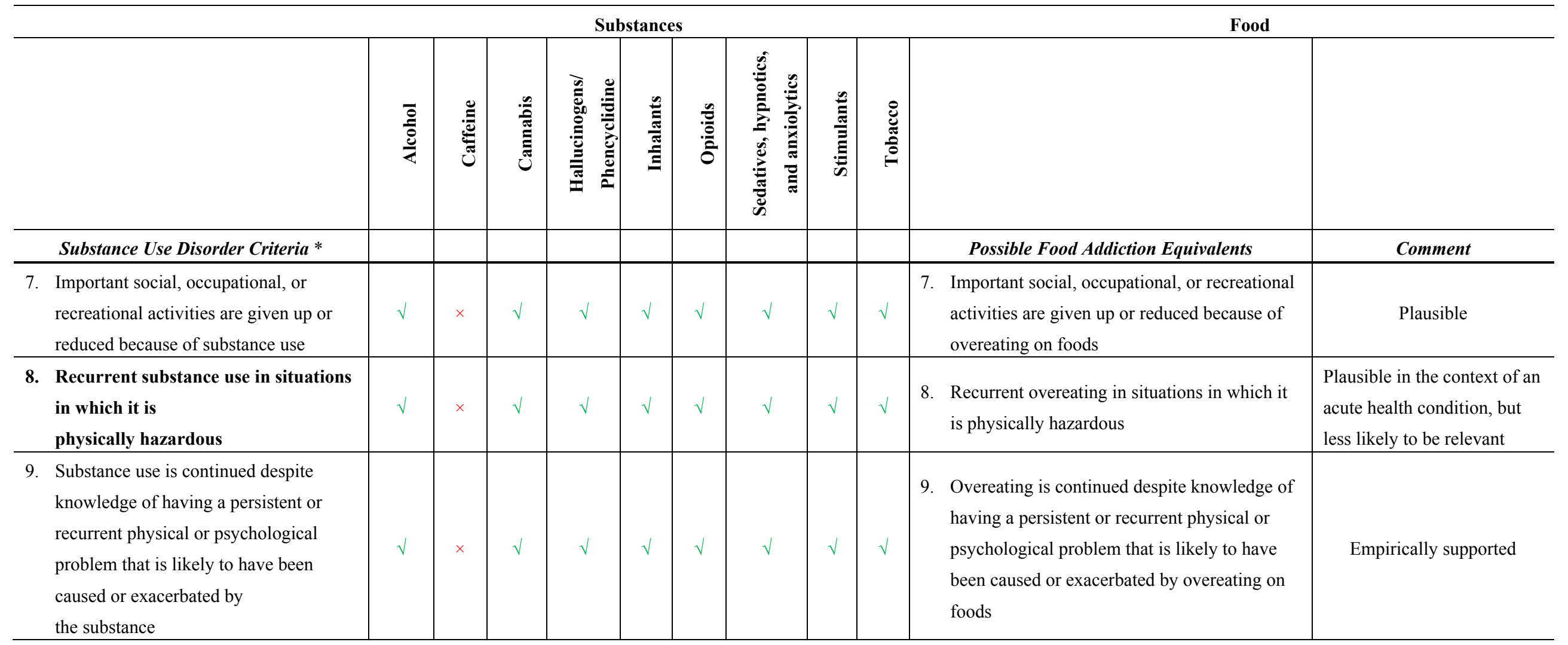


Table 1. Cont.

\begin{tabular}{|c|c|c|c|c|c|c|c|c|c|c|c|}
\hline & \multicolumn{9}{|c|}{ Substances } & \multicolumn{2}{|l|}{ Food } \\
\hline & $\frac{\overline{0}}{\frac{0}{8}}$ & : & Uू. & 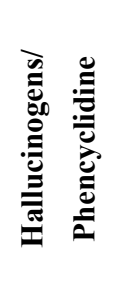 & 参 & on & 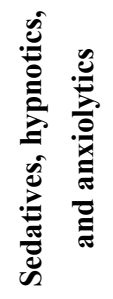 & 离 & 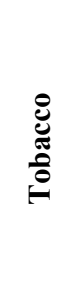 & & \\
\hline Substance Use Disorder Criteria * & & & & & & & & & & Possible Food Addiction Equivalents & Comment \\
\hline 10. Tolerance & \multirow{3}{*}{$\sqrt{ }$} & \multirow{3}{*}{$x$} & \multirow{3}{*}{$\sqrt{ }$} & \multirow{3}{*}{$\sqrt{ }$} & \multirow{3}{*}{$\sqrt{ }$} & \multirow{3}{*}{$\sqrt{ }$} & \multirow{3}{*}{$\sqrt{ }$} & \multirow{3}{*}{$\sqrt{ }$} & \multirow{3}{*}{$\sqrt{ }$} & 10. Tolerance & \multirow{3}{*}{ Plausible } \\
\hline $\begin{array}{l}\text { a. need for markedly increased amounts } \\
\text { of the substance to achieve } \\
\text { intoxication or } \\
\text { desired effect }\end{array}$ & & & & & & & & & & $\begin{array}{l}\text { a. need for markedly increased amounts of } \\
\text { food to achieve desired effect }\end{array}$ & \\
\hline $\begin{array}{l}\text { b markedly diminished effect with } \\
\text { continued use of the same amount of } \\
\text { the substance }\end{array}$ & & & & & & & & & & $\begin{array}{l}\text { b markedly diminished effect with } \\
\text { continued use of the same amount of } \\
\text { food }\end{array}$ & \\
\hline 11. Withdrawal & \multirow{3}{*}{$\sqrt{ }$} & \multirow{3}{*}{$\sqrt{ }$} & \multirow{3}{*}{$\sqrt{ }$} & \multirow{3}{*}{$x$} & \multirow{3}{*}{$x$} & \multirow{3}{*}{$\sqrt{ }$} & \multirow{3}{*}{$\sqrt{ }$} & \multirow{3}{*}{$\sqrt{ }$} & \multirow{3}{*}{$\sqrt{ }$} & 11. Withdrawal & \multirow{3}{*}{$\begin{array}{l}\text { Plausible, but hard to } \\
\text { distinguish from energy } \\
\text { deficit }\end{array}$} \\
\hline $\begin{array}{l}\text { a. withdrawal syndrome } \\
\text { (differs by substance) }\end{array}$ & & & & & & & & & & $\begin{array}{l}\text { a. withdrawal syndrome when refraining } \\
\text { from eating } \\
\text { specific foods }\end{array}$ & \\
\hline $\begin{array}{l}\text { b substance is taken to relieve or avoid } \\
\text { withdrawal symptoms }\end{array}$ & & & & & & & & & & $\begin{array}{l}\text { b specific foods are eaten to relieve or } \\
\text { avoid } \\
\text { withdrawal symptoms }\end{array}$ & \\
\hline Intoxication & $\sqrt{ }$ & $\sqrt{ }$ & $\sqrt{ }$ & $\sqrt{ }$ & $\sqrt{ }$ & $\sqrt{ }$ & $\sqrt{ }$ & $\sqrt{ }$ & $x$ & $\times$ & No intoxication \\
\hline
\end{tabular}

Notes: Criteria printed in boldface are new in DSM-5. Empirically supported refers to evidence that this symptom can be observed with regard to eating behavior in humans based on different assessment methods. Plausible refers to preliminary evidence that this symptom can be observed with regard to eating behavior based on animal models, anecdotal reports, or self-reports such as the YFAS. * A problematic pattern of substance use leading to clinically significant impairment or distress. Symptoms must occur within the past 12 months. Severity is specified as: mild (2-3 symptoms), moderate (4-5 symptoms), severe (6 or more symptoms). 


\subsection{Social or Interpersonal Problems}

Social and interpersonal problems can clearly be observed in the context of eating behavior. For example, obese individuals report heightened levels of social isolation as compared to people with normal weight [65]. While this is likely a result of weight gain, it has also been found that interpersonal problems such as interpersonal distrust, social insecurity, or hostility are linked to binge eating behavior, independent of body mass $[66,67]$. The relationship between binge eating and interpersonal problems is likely a bidirectional one. That is, interpersonal problems may foster negative affect and earlier onset of BED, but binge eating might as well exacerbate and maintain interpersonal problems $[68,69]$. This is also reflected in the fact that both Cognitive-Behavioral Therapy (which focuses directly on eating behavior) and Interpersonal Psychotherapy (which focuses on interpersonal relationships) appear to be similarly effective in the treatment of BED [70,71]. Nevertheless, future studies are needed showing that addiction-like eating is causally involved in social and interpersonal problems. This may be assessed with questions like "I avoided social situations because people do not approve of the way I eat" or "I got in arguments with my family or friends because of the way I eat" in future versions of the YFAS.

\subsection{Use in Physically Hazardous Situations}

The symptom of recurrent substance use in situations that are potentially physically hazardous mainly refers to effects of intoxication, for example, that it is dangerous to handle machines or driving a car after consumption of alcohol. Eating food, of course, does not involve intoxication. However, as described above there is also no intoxication for tobacco. Instead, it is indicated in the DSM-5 that, for tobacco, this criterion may refer to smoking in bed, which increases the risk of starting a fire. Following this line of thought, it could also be argued that this symptom could be endorsed with regard to eating when it refers to, for example, eating while driving. It is widely known that eating while driving impairs driving performance and increases the risk for crashes [72-74]. A further prerequisite for the applicability of this symptom to food addiction would be, of course, studies showing that patients with BN, BED, obesity, or individuals receiving a YFAS diagnosis, actually engage more often in eating while driving (or similar situations) as compared to control subjects. To our knowledge, no such studies exist yet.

Another interpretation of this symptom could be that it refers to food consumption in the context of an acute health condition associated with obesity. For example, this may refer to eating lots of sugar despite being diabetic or overeat on the wrong foods after bariatric surgery. As hazardous effects would be a result of weight gain rather than a direct consequence of eating behavior, we would argue that, like tobacco, this symptom is likely to be less relevant in food addiction because of the absence of intoxication.

\section{Gambling Disorder and Overeating}

Besides the revised SUD criteria, gambling disorder has now been added as a non-substance-related disorder [54]. Diagnostic criteria include (1) a need to gamble with increasing amounts of money in order to achieve the desired excitement; (2) being restless or irritable when attempting to cut down or 
stop gambling; (3) repeated unsuccessful efforts to control, cut back, or stop gambling; (4) a preoccupation with gambling; (5) gambling when feeling distressed; (6) after losing money gambling, returning another day to get even; (7) lying to conceal the extent of involvement with gambling; (8) jeopardizing or losing significant relationships, jobs, or educational or career opportunities because of gambling; and (9) relying on others to provide money to relieve desperate financial situations caused by gambling (Table 2). Gambling disorder can be diagnosed as mild (four to five criteria met), moderate (six to seven criteria met), or severe (eight to nine criteria met), when symptoms were present in the past year.

Some of the gambling disorder criteria can conceivably be applied to eating behavior. For example, repeated unsuccessful efforts to control, cut back, or stop the behavior is a core feature of BN, BED, and food addiction as measured with the YFAS (see above). Moreover, studies using the YFAS consistently show that food addiction is strongly associated with a preoccupation with food and eating and with overeating when feeling distressed [37,39,48,49,64,75]. As with withdrawal syndrome in SUDs, a restlessness or irritability when attempting to cut down or stop overeating seems plausible. Using the YFAS, almost $30 \%$ of obese individuals and up to $50 \%$ of obese individuals with BED report regular experiences of such withdrawal symptoms when cutting down on certain foods [48-50]. However, these subjective reports are potentially biased as it may be hard for respondents to distinguish between symptoms emerging from a general energy deficit (i.e., consuming not enough calories) and those that are actually associated with avoiding specific foods.

The criterion of the need to gamble with increasing amounts of money in order to achieve the desired excitement may be translated to a need to eat increasing amounts of food in order to achieve the desired satisfaction. This definition would be, thus, equal to the SUDs' tolerance criterion, which has been shown to be endorsed by a substantial proportion (approximately 50\%-60\%) of obese individuals in studies using the YFAS [48-50]. However, this criterion may not be applicable to eating when keeping the reference to a feeling of excitement when engaging in the behavior.

Other symptoms seem transferable when substituting the term gambling with overeating (Table 2). Individuals with BN or BED usually experience marked feelings of shame and, thus, conceal their binge eating and this often involves deceiving others about the extent of involvement with overeating [76]. Jeopardizing or loss of a significant relationship, job, or educational or career opportunity may most likely occur because of weight gain. For example, there is experimental evidence showing that human resource professionals underestimate the occupational prestige of obese individuals and would less likely hire them [77]. Regarding the criterion of desperate financial situations caused by gambling, the money spent on binge foods markedly affects quality of life in individuals with $\mathrm{BN}$ and $\mathrm{BED}$, the latter of which are in particular bothered by financial problems [78,79]. Although binge eating involves spending substantial amounts of money, actually plunging into debt or borrowing money from other people to finance overeating probably only occurs in rare cases. Finally, the symptom of returning another day to get even after losing money gambling does neither seem to be transferable to eating behavior nor to SUDs. 
Table 2. Gambling disorder criteria according to the DSM-5 and possible corresponding food addiction criteria.

\begin{tabular}{|c|c|c|}
\hline Gambling Disorder * & Possible Food Addiction Equivalents & Comment \\
\hline $\begin{array}{l}\text { 1. Need to gamble with increasing amounts of money in order to achieve the desired } \\
\text { excitement }\end{array}$ & $\begin{array}{l}\text { 1. Need to eat increasing amounts of food in order to achieve the } \\
\text { desired satisfaction }\end{array}$ & $\begin{array}{l}\text { Plausible, but not applicable when } \\
\text { referring to excitement }\end{array}$ \\
\hline 2. Restlessness or irritability when attempting to cut down or stop gambling & $\begin{array}{l}\text { 2. Restlessness or irritability when attempting to cut down or stop } \\
\text { overeating }\end{array}$ & $\begin{array}{l}\text { Plausible, but hard to distinguish } \\
\text { from energy deficit }\end{array}$ \\
\hline 3. Repeated unsuccessful efforts to control, cut back, or stop gambling & $\begin{array}{l}\text { 3. Repeated unsuccessful efforts to control, cut back, or stop } \\
\text { overeating }\end{array}$ & Empirically supported \\
\hline 4. Preoccupation with gambling & 4. Preoccupation with food and eating & Empirically supported \\
\hline 5. Gambling when feeling distressed & 5. (Over-)eating when feeling distressed & Empirically supported \\
\hline 6. After losing money gambling, often return another day to get even & $\times$ & Not applicable \\
\hline 7. Lying to conceal the extent of involvement with gambling & Lying to conceal the extent of involvement with overeating & Plausible \\
\hline $\begin{array}{l}\text { 8. Jeopardizing or loss of a significant relationship, job, or educational or career } \\
\text { opportunity because of gambling }\end{array}$ & $\begin{array}{l}\text { 8. Jeopardizing or loss of a significant relationship, job, or } \\
\text { educational or career opportunity because of overeating }\end{array}$ & Plausible \\
\hline $\begin{array}{l}\text { 9. Relying on others to provide money to relieve desperate financial situations caused } \\
\text { by gambling }\end{array}$ & $\begin{array}{l}\text { 9. Relying on others to provide money to relieve desperate financial } \\
\text { situations caused by overeating }\end{array}$ & Plausible, but unusual \\
\hline
\end{tabular}

Notes: Empirically supported refers to evidence that this symptom can be observed with regard to eating behavior in humans based on different assessment methods. Plausible refers to preliminary evidence that this symptom can be observed with regard to eating behavior based on animal models, anecdotal reports, or self-reports such as the YFAS. * Persistent and recurrent problematic gambling behavior leading to clinically significant impairment or distress. Symptoms must occur within the past 12 months. Severity is specified as: mild (4-5 symptoms), moderate (6-7 symptoms), severe (8-9 symptoms) 


\section{Implications of the Research Domain Criteria for Food Addiction Research}

Recently, the Research Domain Criteria (RDoC) have been introduced as a new approach to classifying mental illnesses, although it is important to note that the $\mathrm{RDoC}$ is designed as a research framework rather than an alternative diagnostic framework [80-82]. The RDoC approach is designed to focus on domains that reflect neurobiological, physiological, genetic and behavioral underpinnings. The current domains focus on positive valence, negative valence, cognitive functioning, social processes, and arousal/regulation [80]. Critics of the DSM suggest that the focus on "theory free" assessment has limited the incorporation of scientific advances into the diagnostic framework [82]. Thus, in its current form, the DSM may not adequately reflect knowledge gained in the areas of genetic, physiological, and neurobiological research. Although the $\mathrm{RDoC}$ system is not designed to be implemented as a diagnostic method in clinical settings, it is likely to be a major guiding factor in scientific evaluations of psychopathology and will hopefully improve treatment effectiveness [80].

The RDoC approach to diagnosis will also likely guide research on whether an addictive process contributes to certain types of overeating. Binge eating disorder appears to be related to many of the mechanisms implicated in addictive disorders, including elevated motivation to seek out palatable foods, greater neural activation in reward-related circuitry to high-calorie food cues, and limitations in cognitive control $[23,83]$. However, individuals with a BED diagnosis are not homogenous, with a subtype that is indicated by high-levels of dietary restraint and another subtype that exhibits greater negative affect, impulsivity, and overall pathology [84,85]. These two subtypes of BED could potentially be driven by different mechanisms with an addictive process possibly contributing to the latter subtype (but not the former). Thus, some (but not all individuals) with a BED diagnosis may experience an addictive response to certain foods.

Finally, one of the major proposed mechanisms underlying addiction is the ability of an addictive substance/behavior to alter underlying systems in a manner that drives problematic behavior [86]. In other words, individual risk factors (e.g., impulsivity, reward sensitivity, negative affect) interact with the addictive potential of a substance/behavior to result in pathology. As the RDoC approach highlights the importance of identifying mechanisms, examining whether certain foods or ingredients in foods are capable of altering the system in a manner that is akin to addictive substances/behaviors will be an essential line of research. There has been significant progress in this area using animal models of eating behavior [87-89], but research in humans is limited. Addressing this gap in the literature is extremely important for evaluating the validity of the food addiction concept. In sum, the RDoC system will be important for the evaluation of the concept of food addiction as it highlights moving beyond shared signs and symptoms and instead focuses on evaluating whether the etiology and underpinnings of addictions are contributing to compulsive food consumption.

\section{Implications of the Revised Criteria for Food Addiction Research}

\subsection{Is Food Addiction an SUD or Behavioral Addiction?}

The inclusion of gambling disorder as a behavioral addiction along with SUDs in DSM-5 necessitates a discussion if food addiction more resonates with the criteria used for SUDs or with those used for gambling disorder. The term food addiction a priori implies that consumption of a substance 
(or in this case, several substances that combine as food) is essential to this kind of addiction. Research into what foods (or ingredients in certain foods) may be addictive is in its nascent stages. It is possible that some symptoms of addiction may be prominent with certain kinds of food. For example, animal models suggest that sugar may be more associated with withdrawal symptoms than fat [87]. It is also possible that there may be symptoms unique to an addictive-response to highly processed foods relative to drugs of abuse, but future research is needed. Besides the potential relevance of specific types of foods/ingredients, however, research has also highlighted that specific eating patterns (or eating topography) may be necessary in order that food develops its addictive properties. Specifically, it has been found that food addiction symptoms particularly can be observed when high-calorie foods are consumed with alternating periods of restriction and bingeing [12,22].

Likewise, food addiction shows parallels to both SUDs and gambling disorder. We would argue, however, that the SUD criteria could more unambiguously be translated to food and eating. For example, gambling disorder includes symptoms that specifically refer to the money lost during gambling (criteria 1, 6, and 9), which hardly can be applied to eating. Thus, although food addiction may represent a mixture of an SUD and a behavioral addiction, we conclude that the DSM-5 SUD criteria rather than those for gambling disorder should guide future research on food addiction.

\subsection{Will Using the New SUD Criteria Increase or Decrease the Prevalence of Food Addiction?}

In DSM-IV, substance dependence could be diagnosed when at least three symptoms were presented. This threshold was substituted by different severity levels and SUD with mild severity can now be diagnosed when at least two symptoms are present. This will likely increase prevalence for food addiction. For instance, a recent study by Curtis and Davis [90] used a semi-structured interview among obese individuals with and without BED focusing on their experience of their binge eating or overeating, respectively. They found that all participants with BED $(n=12)$ and $42 \%$ (5 out of 12$)$ of those without BED met the mild severity criteria for SUD, which exceeds prevalence estimations of food addiction based on the YFAS [91,92]. Notably, participants rarely mentioned three out of the four new criteria as being core problems associated with their eating [90]. In line with findings of studies using the YFAS, two of the most often reported symptoms were taken in larger amounts of food and unsuccessful attempts to cut down, regardless if individuals had BED or not. In addition, obese individuals with BED most often fulfilled the criteria of continued use despite problems and frequent experiences of craving [90].

Thus, using the mild severity threshold may overestimate food addiction prevalence, as most individuals with obesity, but also many non-obese individuals who struggle with dieting, overeating, and overweight may endorse at least two symptoms. Additionally, individuals with clinically relevant binge eating will likely receive a diagnosis with at least moderate severity (four to five symptoms), which is partly due to the inclusion of the new craving criterion. The DSM-5 indicates that mental disorders, such as addiction, result in clinically significant impairment or distress [54]. In addition to symptoms, the YFAS also assesses whether clinically relevant levels of difficulties are present [37]. It may be important to consider clinical severity regarding the application of DSM-5 to addictive-like eating as an exclusion criterion. 


\subsection{Is a Revision of the YFAS Necessary?}

Given the large overlap between the old and new SUD criteria, we would argue that the YFAS will still be useful for future examinations of food addiction. However, a new version is likely needed to evaluate the questions raised above and, thus, is currently under development. A crucial aspect here is the importance of examining thresholds, particularly for the craving criterion. Although more frequent and intense food cravings are associated with binge eating or YFAS scores [44,45,64,90], food craving per se is a common experience in humans that is not associated with disordered eating or significant distress in most individuals [93]. Thus, simply asking participants if they sometimes experience food craving or not will likely result in high sensitivity, but low specificity for diagnosing food addiction.

\section{Conclusions}

Research on the DSM-IV diagnostic criteria for substance dependence shows that they can be translated to eating behavior and that many individuals with obesity and/or BED fulfill those criteria based on self-report measures such as the YFAS. With regard to the newly added criteria in DSM-5, one study shows that three out of four symptoms may be less relevant in the context of food and eating [90]. However, this was a small-sized qualitative study based on the themes that participants spontaneously mentioned during a semi-structured interview. As we have outlined above, all of the new symptoms can conceivably be applied to eating. Thus, future studies using standardized measures such as a revised YFAS are necessary for appropriately evaluating the relevance of the new SUD criteria for food addiction.

Even if it turns out that the new symptoms, except craving, do not occur in the context of food and eating, it may still be questioned if this would disprove the existence of food addiction. As can be seen in Table 1, the diagnostic criteria as outlined in the DSM-5 do not apply to each substance to the same extent. Specifically, there are SUDs that do not cover the full range of symptoms (caffeine, hallucinogens, inhalants) or do not include intoxication (tobacco). In addition to this, the DSM criteria in general have been criticized for being rather inappropriate for tobacco [94]. Also, the DSM is criticized for its lack of focus on underlying mechanisms, which is a central component of the newly proposed RDoC system. Thus, a major test of the food addiction hypothesis will be to not only focus on the signs and symptoms linking addiction and problematic eating behavior, but also to examine the similarities and differences in the underpinnings of these conditions.

To conclude, we think that the DSM-5 criteria may be valuable for food addiction research, even if some of those symptoms may rarely be endorsed by participants exhibiting addiction-like eating. On the other hand, using those criteria for diagnosing food addiction entails the risk to overestimate the occurrence of food addiction. Thus, future investigations need to take great care that the new SUD criteria are properly translated to food and eating and that reasonable diagnostic thresholds are applied when diagnosing food addiction. Finally, we emphasize the need to think more mechanistically in the evaluation of food addiction by examining the contribution of biological, psychological, and behavioral circuits implicated in addiction to problematic eating behaviors. 


\section{Author Contributions}

Both authors wrote and revised this manuscript in close collaboration.

\section{Conflicts of Interest}

The authors declare no conflict of interest.

\section{References}

1. Randolph, T.G. The descriptive features of food addiction: Addictive eating and drinking. Q. J. Stud. Alcohol 1956, 17, 198-224.

2. Hetherington, M.M.; Macdiarmid, J.I. "Chocolate addiction": A preliminary study of its description and its relationship to problem eating. Appetite 1993, 21, 233-246.

3. Rogers, P.J.; Smit, H.J. Food craving and food "addiction": A critical review of the evidence from a biopsychosocial perspective. Pharmacol. Biochem. Behav. 2000, 66, 3-14.

4. Swanson, D.W.; Dinello, F.A. Follow-up of patients starved for obesity. Psychosom. Med. 1970, 32, 209-214.

5. Szmukler, G.I.; Tantam, D. Anorexia nervosa: Starvation dependence. Br. J. Med. Psychol. 1984, 57, 303-310.

6. Vandereycken, W. The addiction model in eating disorders: Some critical remarks and a selected bibliography. Int. J. Eat. Disord. 1990, 9, 95-101.

7. Wilson, G.T., The addiction model of eating disorders: A critical analysis. Adv. Behav. Res. Ther. 1991, 13, 27-72.

8. De Silva, P.; Eysenck, S. Personality and addictiveness in anorexic and bulimic patients. Personal. Individ. Differ. 1987, 8, 749-751.

9. Gearhardt, A.N.; Davis, C.; Kuschner, R.; Brownell, K.D. The addiction potential of hyperpalatable foods. Curr. Drug Abus. Rev. 2011, 4, 140-145.

10. Schienle, A.; Schäfer, A.; Hermann, A.; Vaitl, D. Binge-eating disorder: Reward sensitivity and brain activation to images of food. Biol. Psychiatry 2009, 65, 654-661.

11. Wang, G.J.; Volkow, N.D.; Logan, J.; Pappas, N.R.; Wong, C.T.; Zhu, W.; Netusil, N.; Fowler, J.S. Brain dopamine and obesity. Lancet 2001, 357, 354-357.

12. Avena, N.M.; Rada, P.; Hoebel, B.G. Evidence for sugar addiction: Behavioral and neurochemical effects of intermittent, excessive sugar intake. Neurosci. Biobehav. Rev. 2008, 32, 20-39.

13. Ahmed, S.H.; Guillem, K.; Vandaele, Y. Sugar addiction: Pushing the drug-sugar analogy to the limit. Curr. Opin. Clin. Nutr. Metab. Care 2013, 16, 434-439.

14. Avena, N.M.; Gold, J.A.; Kroll, C.; Gold, M.S. Further developments in the neurobiology of food and addiction: Update on the state of the science. Nutrition 2012, 28, 341-343.

15. Tang, D.W.; Fellows, L.K.; Small, D.M.; Dagher, A. Food and drug cues activate similar brain regions: A meta-analysis of functional mri studies. Physiol. Behav. 2012, 106, 317-324.

16. Volkow, N.D.; Wang, G.-J.; Tomasi, D.; Baler, R.D. The addictive dimensionality of obesity. Biol. Psychiatry 2013, 73, 811-818. 
17. Volkow, N.D.; Wang, G.-J.; Tomasi, D.; Baler, R.D. Obesity and addiction: Neurobiological overlaps. Obes. Rev. 2013, 14, 2-18.

18. American Psychiatric Association. Diagnostic and Statistical Manual of Mental Disorders, 4th ed.; American Psychiatric Association: Washington, DC, USA, 1994.

19. Albayrak, O.; Wölfle, S.M.; Hebebrand, J. Does food addiction exist? A phenomenological discussion based on the psychiatric classification of substance-related disorders and addiction. Obes. Facts 2012, 5, 165-179.

20. Allen, P.J.; Batra, P.; Geiger, B.M.; Wommack, T.; Gilhooly, C.; Pothos, E.N. Rationale and consequences of reclassifying obesity as an addictive disorder: Neurobiology, food environment and social policy perspectives. Physiol. Behav. 2012, 107, 126-137.

21. Barry, D.; Clarke, M.; Petry, N.M. Obesity and its relationship to addictions: Is overeating a form of addictive behavior? Am. J. Addict. 2009, 18, 439-451.

22. Corsica, J.A.; Pelchat, M.L. Food addiction: True or false? Curr. Opin. Gastroenterol. 2010, 26, 165-169.

23. Davis, C. Compulsive overeating as an addictive behavior: Overlap between food addiction and binge eating disorder. Curr. Obes. Rep. 2013, 2, 171-178.

24. Davis, C.; Carter, J.C. Compulsive overeating as an addiction disorder. A review of theory and evidence. Appetite 2009, 53, 1-8.

25. Drewnowski, A.; Bellisle, F. Is sweetness addictive? Nutr. Bull. 2007, 32, 52-60.

26. Gearhardt, A.N.; Corbin, W.R.; Brownell, K.D. Food addiction-An examination of the diagnostic criteria for dependence. J. Addict. Med. 2009, 3, 1-7.

27. Ifland, J.R.; Preuss, H.G.; Marcus, M.T.; Rourk, K.M.; Taylor, W.C.; Burau, K.; Jacobs, W.S.; Kadish, W.; Manso, G. Refined food addiction: A classic substance use disorder. Med. Hypotheses 2009, 72, 518-526.

28. Pelchat, M.L. Food addiction in humans. J. Nutr. 2009, 139, 620-622.

29. Umberg, E.N.; Shader, R.I.; Hsu, L.K.; Greenblatt, D.J. From disordered eating to addiction: The "food drug" in bulimia nervosa. J. Clin. Psychopharmacol. 2012, 32, 376-389.

30. Wilson, G.T. Eating disorders, obesity and addiction. Eur. Eat. Disord. Rev. 2010, 18, 341-351.

31. Avena, N.M.; Gearhardt, A.N.; Gold, M.S.; Wang, G.-J.; Potenza, M.N. Tossing the baby out with the bathwater after a brief rinse? The potential downside of dismissing food addiction based on limited data. Nat. Rev. Neurosci. 2012, 13, 514.

32. Meule, A.; Kübler, A. The translation of substance dependence criteria to food-related behaviors: Different views and interpretations. Front. Psychiatry 2012, 3, doi:10.3389/fpsyt.2012.00064.

33. Ziauddeen, H.; Farooqi, I.S.; Fletcher, P.C. Obesity and the brain: How convincing is the addiction model? Nat. Rev. Neurosci. 2012, 13, 279-286.

34. Ziauddeen, H.; Farooqi, I.S.; Fletcher, P.C. Food addiction: Is there a baby in the bathwater? Nat. Rev. Neurosci. 2012, 13, 514.

35. Meule, A. Are certain foods addictive? Front. Psychiatry 2014, doi:10.3389/fpsyt.2014.00038.

36. Cassin, S.E.; von Ranson, K.M. Is binge eating experienced as an addiction? Appetite 2007, 49, 687-690.

37. Gearhardt, A.N.; Corbin, W.R.; Brownell, K.D. Preliminary validation of the Yale Food Addiction Scale. Appetite 2009, 52, 430-436. 
38. Meule, A.; Gearhardt, A.N. Five years of the Yale Food Addiction Scale: Taking stock and moving forward. Curr. Addict. Rep. 2014, 1, 193-205.

39. Meule, A.; Vögele, C.; Kübler, A. German translation and validation of the Yale Food Addiction Scale. Diagnostica 2012, 58, 115-126.

40. Pedram, P.; Wadden, D.; Amini, P.; Gulliver, W.; Randell, E.; Cahill, F.; Vasdev, S.; Goodridge, A.; Carter, J.C.; Zhai, G.; et al. Food addiction: Its prevalence and significant association with obesity in the general population. PLoS One 2013, 8, e74832.

41. Mason, S.M.; Flint, A.J.; Field, A.E.; Austin, S.B.; Rich-Edwards, J.W. Abuse victimization in childhood or adolescence and risk of food addiction in adult women. Obesity 2013, 21, E775-E781.

42. Flint, A.J.; Gearhardt, A.N.; Corbin, W.R.; Brownell, K.D.; Field, A.E.; Rimm, E.B. Food addiction scale measurement in 2 cohorts of middle-aged and older women. Am. J. Clin. Nutr. 2014, 99, 578-586.

43. Burmeister, J.M.; Hinman, N.; Koball, A.; Hoffmann, D.A.; Carels, R.A. Food addiction in adults seeking weight loss treatment. Implications for psychosocial health and weight loss. Appetite 2013, 60, 103-110.

44. Davis, C.; Curtis, C.; Levitan, R.D.; Carter, J.C.; Kaplan, A.S.; Kennedy, J.L. Evidence that "food addiction" is a valid phenotype of obesity. Appetite 2011, 57, 711-717.

45. Davis, C.; Loxton, N.J.; Levitan, R.D.; Kaplan, A.S.; Carter, J.C.; Kennedy, J.L. "Food addiction" and its association with a dopaminergic multilocus genetic profile. Physiol. Behav. 2013, 118, 63-69.

46. Eichen, D.M.; Lent, M.R.; Goldbacher, E.; Foster, G.D. Exploration of "food addiction" in overweight and obese treatment-seeking adults. Appetite 2013, 67, 22-24.

47. Lent, M.R.; Eichen, D.M.; Goldbacher, E.; Wadden, T.A.; Foster, G.D. Relationship of food addiction to weight loss and attrition during obesity treatment. Obesity 2014, 22, 52-55.

48. Gearhardt, A.N.; White, M.A.; Masheb, R.M.; Grilo, C.M. An examination of food addiction in a racially diverse sample of obese patients with binge eating disorder in primary care settings. Compr. Psychiatry 2013, 54, 500-505.

49. Gearhardt, A.N.; White, M.A.; Masheb, R.M.; Morgan, P.T.; Crosby, R.D.; Grilo, C.M. An examination of the food addiction construct in obese patients with binge eating disorder. Int. J. Eat. Disord. 2012, 45, 657-663.

50. Meule, A.; Heckel, D.; Kübler, A. Factor structure and item analysis of the Yale Food Addiction Scale in obese candidates for bariatric surgery. Eur. Eat. Disord. Rev. 2012, 20, 419-422.

51. Clark, S.M.; Saules, K.K. Validation of the Yale Food Addiction Scale among a weight-loss surgery population. Eat. Behav. 2013, 14, 216-219.

52. Gearhardt, A.N.; Corbin, W.R.; Brownell, K.D. Instruction sheet for the Yale Food Addiction Scale. Available online: http://www.yaleruddcenter.org/resources/upload/docs/what/addiction/ FoodAddictionScaleInstructions09.pdf (accessed on 5 September 2014).

53. Meule, A.; Hermann, T.; Kübler, A. Food addiction in overweight and obese adolescents seeking weight-loss treatment. Adipositas 2013, 7, A48.

54. American Psychiatric Association. Diagnostic and Statistical Manual of Mental Disorders, 5th ed.; American Psychiatric Association: Washington, DC, USA, 2013. 
55. Tiffany, S.T.; Wray, J.M. The clinical significance of drug craving. Ann. N. Y. Acad. Sci. 2012, $1248,1-17$.

56. Hormes, J.M.; Rozin, P. Does "craving" carve nature at the joints? Absence of a synonym for craving in many languages. Addict. Behav. 2010, 35, 459-463.

57. Weingarten, H.P.; Elston, D. Food cravings in a college population. Appetite 1991, 17, 167-175.

58. Komatsu, S. Rice and sushi cravings: A preliminary study of food craving among Japanese females. Appetite 2008, 50, 353-358.

59. Kühn, S.; Gallinat, J. Common biology of craving across legal and illegal drugs-A quantitative meta-analysis of cue-reactivity brain response. Eur. J. Neurosci. 2011, 33, 1318-1326.

60. Naqvi, N.H.; Bechara, A. The hidden island of addiction: The insula. Trends Neurosci. 2009, 32, $56-67$.

61. Pelchat, M.L.; Johnson, A.; Chan, R.; Valdez, J.; Ragland, J.D. Images of desire: Food-craving activation during fmri. NeuroImage 2004, 23, 1486-1493.

62. Van den Eynde, F.; Koskina, A.; Syrad, H.; Guillaume, S.; Broadbent, H.; Campbell, I.C.; Schmidt, U. State and trait food craving in people with bulimic eating disorders. Eat. Behav. 2012, 13, 414-417.

63. Abilés, V.; Rodríguez-Ruiz, S.; Abilés, J.; Mellado, C.; García, A.; Pérez de la Cruz, A.; Fernández-Santaella, M.C. Psychological characteristics of morbidly obese candidates for bariatric surgery. Obes. Surg. 2010, 20, 161-167.

64. Meule, A.; Kübler, A. Food cravings in food addiction: The distinct role of positive reinforcement. Eat. Behav. 2012, 13, 252-255.

65. Anderson, K.; Rieger, E.; Caterson, I. A comparison of maladaptive schemata in treatment-seeking obese adults and normal-weight control subjects. J. Psychosom. Res. 2006, 60, 245-252.

66. Lo Coco, G.; Gullo, S.; Salerno, L.; Iacoponelli, R. The association among interpersonal problems, binge behaviors, and self-esteem, in the assessment of obese individuals. Compr. Psychiatry 2011, $52,164-170$.

67. Fassino, S.; Leombruni, P.; Piero, A.; Abbate-Daga, G.; Rovera, G.G. Mood, eating attitudes, and anger in obese women with and without binge eating disorder. J. Psychosom. Res. 2003, 54, $559-566$.

68. Ansell, E.B.; Grilo, C.M.; White, M.A. Examining the interpersonal model of binge eating and loss of control over eating in women. Int. J. Eat. Disord. 2012, 45, 43-50.

69. Blomquist, K.K.; Ansell, E.B.; White, M.A.; Masheb, R.M.; Grilo, C.M. Interpersonal problems and developmental trajectories of binge eating disorder. Compr. Psychiatry 2012, 53, 1088-1095.

70. Hilbert, A.; Bishop, M.E.; Stein, R.I.; Tanofsky-Kraff, M.; Swenson, A.K.; Welch, R.R.; Wilfley, D.E. Long-term efficacy of psychological treatments for binge eating disorder. Br. J. Psychiatry 2012, 200, 232-237.

71. Wilson, G.T.; Wilfley, D.E.; Agras, W.S.; Bryson, S.W. Psychological treatments of binge eating disorder. Arch. Gen. Psychiatry 2010, 67, 94-101.

72. Alosco, M.L.; Spitznagel, M.B.; Fischer, K.H.; Miller, L.A.; Pillai, V.; Hughes, J.; Gunstad, J. Both texting and eating are associated with impaired simulated driving performance. Traffic Inj. Prev. 2012, 13, 468-475. 
73. Stutts, J.; Feaganes, J.; Reinfurt, D.; Rodgman, E.; Hamlett, C.; Gish, K.; Staplin, L. Driver's exposure to distractions in their natural driving environment. Accid. Anal. Prev. 2005, 37, 1093-1101.

74. Young, M.S.; Mahfoud, J.M.; Walker, G.H.; Jenkins, D.P.; Stanton, N.A. Crash dieting: The effects of eating and drinking on driving performance. Accid. Anal. Prev. 2008, 40, 142-148.

75. Meule, A.; Heckel, D.; Jurowich, C.F.; Vögele, C.; Kübler, A. Correlates of food addiction in obese individuals seeking bariatric surgery. Clin. Obes. 2014, 4, 228-236.

76. Goss, K.; Allan, S. Shame, pride and eating disorders. Clin. Psychol. Psychother. 2009, 16, 303-316.

77. Giel, K.E.; Zipfel, S.; Alizadeh, M.; Schaffeler, N.; Zahn, C.; Wessel, D.; Hesse, F.W.; Thiel, S.; Thiel, A. Stigmatization of obese individuals by human resource professionals: An experimental study. BMC Public Health 2012, 12, 1-9.

78. Agras, W.S. The consequences and costs of the eating disorders. Psychiatr. Clin. N. Am. 2001, 24, 371-379.

79. Johnson, J.G.; Spitzer, R.L.; Williams, J.B.W. Health problems, impairment and illnesses associated with bulimia nervosa and binge eating disorder among primary care and obstetric gynaecology patients. Psychol. Med. 2001, 31, 1455-1466.

80. Cuthbert, B.N.; Insel, T.R. Toward the future of psychiatric diagnosis: The seven pillars of rdoc. BMC Med. 2013, 11, 126.

81. Insel, T.R.; Cuthbert, B.N.; Garvey, M.A.; Heinssen, R.K.; Pine, D.S.; Quinn, K.J.; Sanislow, C.A.; Wang, P.S. Research domain criteria $(\mathrm{RDoC})$ : Toward a new classification framework for research on mental disorders. Am. J. Psychiatry 2010, 167, 748-751.

82. Sanislow, C.A.; Pine, D.S.; Quinn, K.J.; Kozak, M.J.; Garvey, M.A.; Heinssen, R.K.; Wang, P.S.-E.; Cuthbert, B.N. Developing constructs for psychopathology research: Research domain criteria. J. Abnorm. Psychol. 2010, 119, 631-639.

83. Balodis, I.M.; Molina, N.D.; Kober, H.; Worhunsky, P.D.; White, M.A.; Sinha, R.; Grilo, C.M.; Potenza, M.N. Divergent neural substrates of inhibitory control in binge eating disorder relative to other manifestations of obesity. Obesity 2013, 21, 367-377.

84. Stice, E.; Agras, W.S.; Telch, C.F.; Halmi, K.A.; Mitchell, J.E.; Wilson, T. Subtyping binge eating-disordered women along dieting and negative affect dimensions. Int. J. Eat. Disord. 2001, $30,11-27$.

85. Grilo, C.M.; Masheb, R.M.; Wilson, G.T. Subtyping binge eating disorder. J. Consult. Clin. Psychol. 2001, 69, 1066-1072.

86. Volkow, N.D.; Li, T.-K. The neuroscience of addiction. Nat. Neurosci. 2005, 8, 1429-1430.

87. Avena, N.M.; Rada, P.; Hoebel, B.G. Sugar and fat bingeing have notable differences in addictive-like behavior. J. Nutr. 2009, 139, 623-628.

88. Berridge, K.C.; Ho, C.-Y.; Richard, J.M.; DiFeliceantonio, A.G. The tempted brain eats: Pleasure and desire circuits in obesity and eating disorders. Brain Res. 2010, 1350, 43-64.

89. Johnson, P.M.; Kenny, P.J. Dopamine D2 receptors in addiction-like reward dysfunction and compulsive eating in obese rats. Nat. Neurosci. 2010, 13, 635-641.

90. Curtis, C.; Davis, C. A qualitative study of binge eating and obesity from an addiction perspective. Eat. Disord. 2014, 22, 19-32. 
91. Meule, A. How prevalent is "food addiction"? Front. Psychiatry 2011, 2, doi:10.3389/ fpsyt.2011.00061.

92. Meule, A. Food addiction and body-mass-index: A non-linear relationship. Med. Hypotheses 2012, 79, 508-511.

93. Hill, A.J. The psychology of food craving. Proc. Nutr. Soc. 2007, 66, 277-285.

94. Baker, T.B.; Breslau, N.; Covey, L.; Shiffman, S. DSM criteria for tobacco use disorder and tobacco withdrawal: A critique and proposed revisions for DSM-5. Addiction 2012, 107, $263-275$.

(C) 2014 by the authors; licensee MDPI, Basel, Switzerland. This article is an open access article distributed under the terms and conditions of the Creative Commons Attribution license (http://creativecommons.org/licenses/by/3.0/). 